\title{
A ARTICULAÇÃO ENTRE CAPITAL FINANCEIRO E IMOBILIÁRIO NA PRODUÇÃO DO ESPAÇO DA OPERAÇÃO URBANA CONSORCIADA DA REGIÃO DO PORTO DO RIO DE JANEIRO
}

The link between financial and real estate capitals in the spatial production of
Operação Urbana Consorciada da Região do Porto do Rio de Janeiro

\author{
Marcela Virginio Dametto \\ Mestre em Geografia pela PUC-Rio e Doutoranda em Geografia Humana pela USP \\ damettomarcela@gmail.com
}

Artigo recebido em 14/07/2017 e aceito para publicação em 04/09/2017

DOI: 10.12957/tamoios.2017.29551

\section{RESUMO}

As diretrizes criadas por organismos internacionais tal como o Banco Internacional para Reconstrução e Desenvolvimento (BIRD / Banco Mundial) começaram a ser aplicadas no desenvolvimento urbano de cidades capitalistas periféricas a partir dos anos de 1980 e, neste sentido, estão sendo aplicadas atualmente na produção do espaço das regiões central e portuária da cidade do Rio de Janeiro e, mais especificamente, na Operação Urbana Consorciada da Região do Porto do Rio de Janeiro (OUCRPRJ). Essas diretrizes além de espacialmente formais, estabelecem exigências ligadas à solvência financeira da cidade e obedecem à lógica neoliberal que se materializa neste espaço por meio da articulação entre capital financeiro e imobiliário. Nesta perspectiva, este artigo tem o objetivo de analisar os efeitos desta articulação na produção do espaço da referida operação urbana.

Palavras-chave: BIRD/Banco Mundial; produção espacial; neoliberalismo financeirização; OUCRPRJ.

\begin{abstract}
The guidelines created by international organisms such as International Bank for Reconstruction and Development (IRBD / World Bank) started to be applied in the urban development of peripherical capitalist cities since the 80's, and, in that sense, are currently being applied in spatial production of central and harbors areas of Rio de Janeiro's city, and more specifically, into Operação Urbana Consorciada da Região do Porto do Rio de Janeiro (OUCRPRJ). Those guidelines beyond oriented to spatial form, stablish requirements referring to financial solvency and follow neoliberal logic which is materialized in that space through the linkage between financial and real estate capitals. In that matter, this article seeks to analyze the effects of such linkage on the spatial production of OUCRPRJ.
\end{abstract}

Palavras-chave: IRBD/WB; spatial production; neoliberalism; financialization; OUCRPRJ. 


\section{INTRODUÇÃO}

As práticas neoliberais que orientam o desenvolvimento urbano de grande parte das cidades capitalistas contemporâneas são disseminadas por meio de cartilhas desenvolvimentistas desenvolvidas pelo BIRD / Banco Mundial. Neste sentido, o Banco Mundial vem impondo diretrizes e metas a serem cumpridas nas cidades capitalistas periféricas e, portanto, na cidade do Rio de Janeiro, principalmente, em começos do século XXI, momento em que a mundialização financeira se consolidou e a circulação de capital no espaço deve ser facilitada.

A circulação facilitada de capital ${ }^{1}$ foi promovida tanto pelas desregulamentações e liberalizações do sistema financeiro (CHESNAIS, 1996), como pela reestruturação urbano-imobiliária da cidade que possibilitou essa maior fluidez. A aliança entre diversos agentes econômicos e o Estado, representado, neste caso, pelas esferas federal e municipal é viabilizada pelas Parcerias Público-Privadas (PPPs), item obrigatório na lista de exigências do BIRD / Banco Mundial. Segundo o Banco Mundial, as cidades que recebem empréstimos para desenvolver seu espaço urbano e criar a infraestrutura necessária para facilitar a circulação de capital, mercadorias e pessoas, devem apresentar "solvência financeira". Segundo este banco $^{2}$ (2000, p.19):

\footnotetext{
Por solvência financeira se entende aqui a solidez financeira no tratamento das fontes de ingressos e dos gastos e, no caso de algumas cidades, uma capacidade creditícia tal que as permita o acesso aos mercados de capitais. As operações de desenvolvimento urbano do Banco e o correspondente diálogo sobre políticas fomentam a adoção de sistemas claros e coerentes de ingressos e gastos locais, com transferências intergovernamentais transparentes e previsíveis, e prudência no endividamento do município, assim como contabilidade financeira, gestão de ativos e práticas de contratação geralmente aceitas. Para uma boa gestão das finanças urbanas é importante adotar um critério comercial para muitos dos serviços e das funções administrativas das cidades, sem perder de vista os interesses sociais. Este critério comercial também é indispensável para a participação do setor privado ou para a privatização dos serviços urbanos. Nos países e cidades cujos sistemas creditícios municipais seguem sendo rudimentares, o Banco continuará apoiando os intermediários financeiros especializados, como os fundos de desenvolvimento municipal. As operações creditícias devem encorajar cada vez mais a transição a sistemas creditícios municipais em acordo com as leis de mercado, nos quais os departamentos financeiros do Banco e da $\mathrm{CFI}^{3}-$ Corporação Financeira Internacional - podem se apoiar mediante seu trabalho sobre a infraestrutura básica de mercado.
}

Este documento explicita a orientação deste organismo no que diz respeito às privatizações e às Parcerias Público-Privadas. Essas orientações fazem, essencialmente, parte do "pacote" neoliberal, o qual é tomado como panaceia dos problemas fiscais das cidades e promotor do desenvolvimento urbano.

Entretanto, apesar de se pretender global, estas práticas transformam os espaços urbanos de diferentes maneiras, de acordo com suas especificidades sociais, culturais, políticas e econômicas. Sendo assim, o neoliberalismo promoveu desenvolvimentos geográficos desiguais (HARVEY, 2008), na medida em que afetou em diferentes graus os mais diversos espaços. Diante disto, as práticas neoliberais por meio da articulação entre capital financeiro e imobiliário estão sendo aplicadas na produção do espaço do perímetro da Operação Urbana Consorciada da Região do Porto do Rio de Janeiro (OUCRPRJ), localizada nas regiões central e portuária da cidade.

Nesta perspectiva, este artigo tem o objetivo de expor a articulação entre o capital financeiro e o imobiliário no atual momento histórico, tendo como foco analítico a 
produção do espaço da OUCRPRJ, a qual é, predominantemente, orientada pela lógica financeira e por diretrizes definidas pelo BIRD / Banco Mundial. Por sua vez, objetivase de maneira mais específica analisar esta articulação por meio da compreensão da dinâmica de investimentos realizada pela Concessionária do VLT Carioca S.A, cuja responsabilidade é implementar o Veículo Leve sobre Trilhos (VLT) neste espaço. Para realização de tal análise, primeiramente, faz-se a exposição de alguns mecanismos de atuação do BIRD / Banco Mundial, os quais são globais, porém, promovem intensas transformações locais decorrentes da implementação de operações urbanas e, portanto, afetam diretamente o conteúdo social desses espaços.

\section{RELEVÂNCIA DO BANCO MUNDIAL NAS PRÁTICAS NEOLIBERAIS - BIRD}

Na conferência de Bretton Woods, realizada em 1944, estabeleceu-se um sistema regulador da política econômica internacional através da criação de instituições que tinham por objetivo definir regras político-econômicas ao resto do mundo, tal qual o Banco Internacional para Reconstrução e Desenvolvimento - BIRD - que, posteriormente, dividiu-se em Banco Mundial e Fundo Monetário Internacional (FMI).

Nesta perspectiva, observa-se que um dos efeitos pragmáticos originados nesta conferência foi a institucionalização de determinadas práticas político-econômicas impostas aos países capitalistas por meio de instituições como o BIRD, Banco Mundial e FMI que têm a função de facilitar a acumulação e circulação de capital, mercadorias e pessoas através do globo, mesmo apesar de ainda existirem variadas barreiras fiscais e cambiais impostas pelos diferentes Estados-nação.

Apesar da criação destas instituições internacionais reguladoras, a partir de 1970, crises de sobreacumulação e superprodução aliadas à insatisfação popular tomaram o cenário mundial e, portanto, foi necessário reformar o sistema político-econômico para garantir a retomada do processo de acumulação de capital.

Diante disto, a alternativa à crise vinha por meio do neoliberalismo político, econômico e ideológico. Nesta direção, o neoliberalismo enquanto ideologia e práxis foi aplicado a partir dos anos de 1980 com os governos Thatcher na Grã-Bretanha e Reagan nos Estados Unidos da América. Entretanto, neste momento histórico ainda havia discordâncias no que se refere à implementação de políticas econômicas e sociais nos diferentes Estados-nação, o que gerou, posteriormente, diferentes efeitos na aplicação das práticas neoliberais. Esses efeitos se manifestaram no espaço de formas distintas produzindo desenvolvimentos geográficos desiguais. A este respeito, Harvey (2008, p. 23) aponta que:

\footnotetext{
O desenvolvimento geográfico desigual do neoliberalismo, sua aplicação frequentemente parcial e assimétrica de Estado para Estado e de formação social para formação social atestam o caráter não-elaborado das soluções neoliberais e as complexas maneiras pelas quais forças políticas, tradições históricas e arranjos institucionais existentes moldaram em conjunto por que e como o processo de neoliberalização de fato ocorreu.
}

A grosso modo, as práticas neoliberais consistem na desregulamentação e liberalização da atividade financeira, na privatização de serviços públicos, precarização das relações trabalhistas e, finalmente, na atuação dupla do Estado, o qual deve promover o desenvolvimento social da nação ao mesmo tempo em que precisa facilitar a acumulação ampliada de capital.

Nesta perspectiva, atualmente, o Estado brasileiro atua na direção da aplicação das diretrizes impostas pelo BIRD / Banco Mundial no que diz respeito à reestruturação 
da cidade do Rio de Janeiro e mais especificamente do perímetro da OUCRPRJ. Ocorre que as transformações urbanas em curso se materializam por meio tanto de investimentos da esfera federal (Caixa Econômica Federal) como por meio de empréstimos concedidos pelo BIRD / Banco Mundial. Este foi o caso da implementação do VLT nas regiões central e portuária da cidade do Rio de Janeiro.

Neste sentido, diante de um quadro de transformações nas dimensões produtiva e financeira que se materializam no espaço, Henri Lefebvre (2000) reflete sobre o fato de que o espaço é um produto social porque tem sua produção orientada de acordo com as exigências de cada momento histórico. Segundo este autor (2000, p.7):

\begin{abstract}
O espaço não pode mais ser concebido como passivo, vazio, ou então, como os "produtos", não tendo outro sentido senão o de ser trocado, o de ser consumido, o de desaparecer. Enquanto produto, por interação ou retroação, o espaço intervém na própria produção: organização do trabalho produtivo, transportes fluxos de matérias-primas e energias, redes de repartição de produtos. À sua maneira produtivo e produtor, o espaço (mal ou bem organizado) entra nas relações de produção e nas forças produtivas. Seu conceito não pode, portanto, ser isolado e permanecer estático. Ele se dialetiza: produto-produtor, suporte de relações econômicas e sociais.
\end{abstract}

Além de produto-produtor, o espaço foi também tornado mercadoria fundamental para a reprodução continuada de capital, principalmente, em momentos de crise econômica. A concretização do "ajuste estrutural" (HARVEY, 2008) neoliberal a partir dos anos de 1990 gerou processos político-econômicos que aumentaram ainda mais o desemprego e a desigualdade social nos países periféricos por meio, basicamente, da aplicação de medidas austeras que cortaram gastos sociais ao mesmo tempo em que garantiram isenções fiscais e outros benefícios a diversos tipos de atividades produtivas.

Sendo assim, emerge no cenário global uma maneira específica de governar e gerir os gastos públicos, ligada à noção de gestão das cidades e de "governança". O urbano deixa de ser, primordialmente, o espaço do encontro, da festa, dos conflitos e das contradições, para se tornar um espaço fragmentado, hierarquizado e segregado.

A cidade contemporânea torna-se uma empresa que deve ser bem gerida com o objetivo de ser atrativa e, consequentemente, lucrativa. Para promover este tipo de gestão urbana, o BIRD / Banco Mundial orienta a reestruturação urbana do Rio de Janeiro através da elaboração de documentos e concessão de empréstimos.

Diante disto, o Estado brasileiro desempenha um papel fundamental na recepção e execução das orientações definidas pelo BIRD / Banco Mundial, pois tanto em sua esfera federal e, principalmente na municipal, acata as orientações do BIRD / Banco Mundial no que concerne à tomada de decisões que promovem grandes transformações urbanas.

Sendo assim, em março do ano 2000 o Banco Mundial publicou um documento intitulado "Cities in Transition: World Bank Urban and Local Government Strategy", no qual sinaliza a importância das Parcerias Público-Privadas (PPPs) para o crescimento econômico urbano e para a diminuição da pobreza. Este documento estabelece diretrizes específicas que conformariam o ideal de "cidade competitiva". Segundo o Banco Mundial (2000, pp.8-9):

Cada vez mais há provas de que a prestação de serviços múltiplos incrementa o alcance dos benefícios, mas as carências sociais ou institucionais podem minar as estratégias orientadas a estes serviços. É por isso que, desde fins dos oitenta, os projetos urbanos se concentraram de forma crescente na reforma de políticas e em mudanças institucionais, e se aprofundou o diálogo do Banco sobre questões de regulação, sistemas de incentivos e as modalidades de 
relações- entre os governos locais, o setor privado, as organizações informais e as unidades familiares - que determinam como funcionam as cidades. À medida que a democratização, a descentralização e a cooperação entre os setores público e privado fortalecem a comunicação e colaboração entre estes participantes, se requer um enfoque mais holístico de desenvolvimento urbano que aponta a eles a nova estratégia do Banco. A rede de atividades do Banco relacionadas com os temas urbanos está crescendo. Este incremento se produz não só nas operações de desenvolvimento urbano, senão também em outras categorias da pasta, entre elas, abastecimento de água e saneamento básico, e o transporte urbano (que juntos representam outros $6 \%$ do total de financiamento outorgado pelo Banco), meio ambiente, gestão do setor público e setores sociais, onde as necessidades dos governos urbanos e municipais foram se tornando mais evidentes e os organismos paralelos se descentralizaram. Os programas urbanos também estão se intensificando para abarcar outros elementos do desenvolvimento urbano sustentável, como a promoção da economia local, o acesso ao capital privado, a reforma dos mercados imobiliários, a integração dos interesses culturais e a prevenção e o alívio dos efeitos dos desastres ${ }^{4}$. Todos estes fatores exigem uma reação mais enérgica do Banco, que segue sendo o organismo que provê maior assistência para o desenvolvimento urbano com uma perspectiva tanto global como operativa em questões urbanas.

O trecho acima indica a importância do acesso ao capital privado e da reforma dos mercados imobiliários a fim de atingir o desenvolvimento urbano. Além disso, explicita a posição do Banco como importante provedor (credor) de capital na promoção de ações que possibilitam este desenvolvimento.

A forte presença do Banco Mundial na orientação da produção do espaço da cidade do Rio de Janeiro pode ser expressa quando em 2011 aprova-se um empréstimo de US\$ 485 milhões ao Estado do Rio de Janeiro para ser alocado em "políticas de desenvolvimento metropolitano, urbano e de moradia do Rio de Janeiro". Parte deste montante, mais especificamente, US\$ 1.045 milhão foi destinado ao município do Rio de Janeiro com o objetivo de "criar espaço fiscal para investimentos com o intuito de aperfeiçoar a qualidade e eficiência da prestação dos serviços públicos, especialmente nas áreas pobres" $"$.

Entretanto, a Prefeitura do Rio de Janeiro priorizou alguns elementos da cartilha do Banco Mundial focando seus esforços na concretização de obras viárias que reestruturaram o tráfego e, assim, promoveram a aceleração da circulação de capital, mercadorias e pessoas na região portuária. As obras realizadas pela Prefeitura e financiadas por meio da comercialização de Certificados de Potencial Adicional de Construção (CEPACS) seguiram orientações que constam no documento intitulado "Cidades em Movimento" elaborado pelo BIRD / Banco Mundial. Deve-se ressaltar que a reestruturação do complexo viário deste espaço é reflexo do atual contexto histórico, o qual exige transformações espaciais que visam promover a acumulação ampliada de capital e frear qualquer possibilidade na baixa da taxa de lucro.

\section{O PROCESSO DE FINANCEIRIZAÇÃO DA PRODUÇÃO ESPACIAL: VEÍCULO LEVE SOBRE TRILHOS (VLT) NA OUCRPRJ}

As obras de infraestruturas realizadas no perímetro da OUCRPRJ são coordenadas pela Companhia de Desenvolvimento Urbano da Região do Porto do Rio de Janeiro (CDURP), órgão criado especialmente para esta operação urbana, de economia mista e controlado pela Prefeitura. Ao mesmo tempo, as obras de infraestruturas são concretizadas pela Concessionária Porto $\mathrm{Novo}^{7}$ formada pelas empresas Odebrecht $(37,5 \%)$, OAS $(37,5 \%)$ e Carioca Engenharia (25\%). Estas obras se referem, 
principalmente, à implantação de um novo sistema viário que visa garantir a acumulação ampliada de capital por meio da facilitação de sua circulação, assim como promover a inversão do excedente de capital na produção do espaço por meio da articulação entre capital financeiro e imobiliário. Neste sentido, a obra de mobilidade urbana a ser analisada seguidamente é o VLT, justamente, porque expressa a referida articulação em sua concretização.

Em junho de 2013, a Prefeitura da Cidade do Rio de Janeiro contratou a Concessionária do VLT Carioca S.A, composta pelas empresas CCR (24,8750\%), Odebrecht Transport (24,8750\%), Invepar (24,8750\%), RioPar Participações $(24,8750 \%)$, BRt - Benito Roggio Transporte (0,25\% - empresa argentina) e RATP do Brasil (0,25\% - empresa francesa), consolidando mais uma PPP na região portuária. Segundo o site da concessionária: "instrumento de uma política global de mobilidade, a tecnologia do Veículo Leve sobre Trilhos está em operação em mais de 400 cidades e em implantação ou desenvolvimento em cerca de 260 cidades distribuídas nos cinco continentes".

Nesta direção, se existe um padrão global de produção do espaço urbano elaborado e difundido por diretrizes do BIRD / Banco Mundial, a cidade do Rio de Janeiro como mercadoria que compete globalmente, também deve segui-lo. Segundo Fernanda Sánchez (2004, p.42):

\begin{abstract}
Através da formação de um complexo espectro de coalizões sociopolíticas, o governo urbano encarna um dos principais agentes do não menos complexo conjunto de forças que passam a lidar com a cidade, organizando suas feições e sua estrutura espacial e social a essa realidade, ou seja, aos novos tempos do capitalismo globalizado, de corte seletivo e excludente. A competição pelos investimentos instaura uma verdadeira "guerra" entre os lugares, expressão emblemática da subsunção do mundo e da vida contemporâneos à lógica do capital nesses tempos de desmedida empresarial. Nesse ambiente, emerge um conjunto - homogêneo - de orientações que passam a compor uma pauta a ser buscada e colocada em prática pelos diversos administradores urbanos, independentemente de sua filiação político-partidária. Nessa pauta, destacamse as seguintes iniciativas mutuamente determinadas: a formação de parcerias entre os setores público e privado; a implementação de novos instrumentos e instituições voltados para o governo urbano; a desregulamentação e/ou flexibilização do aparato legal da cidade e a redução da escala de intervenção/gestão urbana, por meio de projetos de grande impacto no espaço construído das cidades.
\end{abstract}

Sob esta perspectiva, a produção dos espaços das cidades se dá de forma "homogeneizada" por meio de orientações padronizadas que são executadas pelos governos municipais a fim de atrair investimentos e estabelecer um "clima" favorável aos negócios. Além disso, a execução dos grandes projetos sinalizados pela autora acontece através de "inovações financeiras" como no caso da comercialização dos CEPACS na OUCRPRJ. Mas a novidade do processo estabelecido através de operações urbanas realizadas no município de São Paulo e na OUCRPRJ é a ação de Fundos de Investimentos Imobiliários (FIIs) que funcionam como intermediadores do processo de passagem de capital do setor financeiro para o imobiliário e vice-versa. Além desta passagem, os FIIs concentram capital, o que possibilita seu investimento no mercado secundário e, portanto, sua reprodução através da esfera financeira. Esta condição garante a existência de capital para continuidade das obras de infraestrutura da operação urbana em questão. A concessionária responsável pela implantação do VLT associada à CDURP se apoia nos recursos provenientes do Fundo de Investimento Imobiliário VLT e no 
pagamento de contraprestação pecuniária feito pelo concedente (Prefeitura do Rio de Janeiro - CDURP) para continuar as obras e manter sua taxa de lucro.

O balanço patrimonial da Concessionária do VLT Carioca S.A (ver figura 1) aponta para o fato de que esta concessionária tem o direito incondicional de obter pagamento através de aportes públicos ou contraprestações pecuniárias sob a taxação adicional de 8,47\% ao ano. O contrato de concessão tem duração prevista de 25 anos, revelando o lucro futuro desta concessionária.

Nesta perspectiva, verifica-se que esta PPP beneficia financeiramente a concessionária ao invés de diminuir os gastos públicos à medida que esses continuam a existir sob altas taxas de juros e por longo período. Os chamados Grandes Projetos Urbanos (GPU's) como a OUCRPRJ, utilizam o mecanismo de PPP's com a ideia de desonerar o poder público no que tange aos investimentos nas obras de infraestrutura.

Entretanto, não é isso o que se verifica na prática.

Figura 1: Balanço Patrimonial da Concessionária do VLT Carioca S.A. Fonte: DELLOITE TOUCHE TOHMATSU AUDITORES INDEPENDENTES. Concessionária do VLT Carioca S.A: Informações financeiras intermediárias referentes ao trimestre e semestre findos em 30 de junho de 2015 e Relatório de revisão dos auditores independentes sobre as informações financeiras intermediárias. São Paulo, 2015

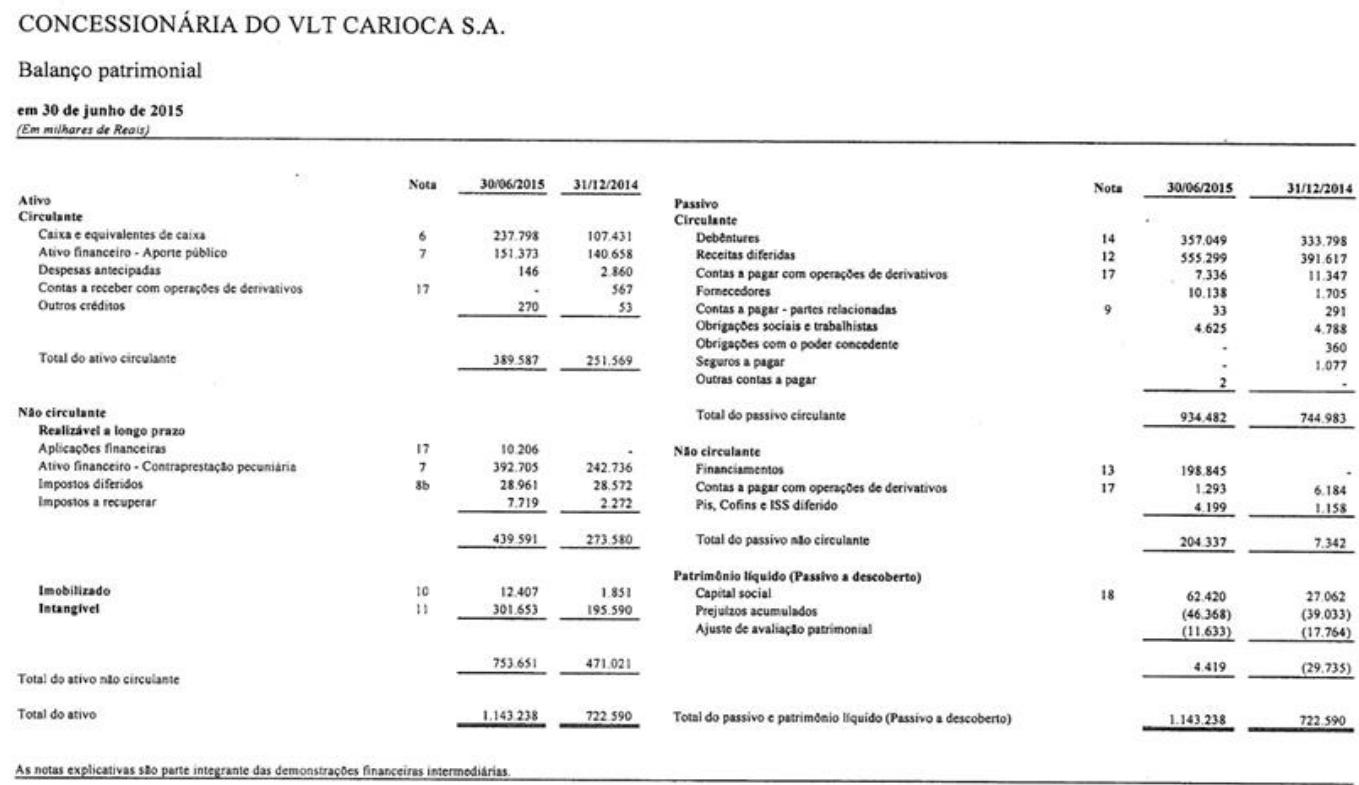

Observa-se que a maior parte da receita da concessionária advém de recursos públicos, seja através do aporte público de $\mathrm{R} \$ 151$ milhões e 373 mil ou do pagamento de contraprestação pecuniária no valor de R \$ 392 milhões e 705 mil. Deve-se ressaltar que a receita referente à contraprestação pecuniária faz parte do ativo não circulante da concessionária, portanto, só poderá se realizar no final do próximo ano de exercício. Mesmo nestas condições, observa-se que a quantia realizável a longo prazo é alta e, portanto, a taxa de lucro da concessionária será mantida. Apesar do passivo circulante apresentado neste balanço ser superior ao ativo circulante em R \$ 544 milhões e 895 mil, 
deve-se atentar à verdadeira razão desta discrepância. Neste sentido, o documento explica que:

Em 30 de junho de 2015, a Companhia possui capital circulante líquido negativo de $\mathrm{R} \$ 544.895$, ( $\mathrm{R} \$ 493.414$ em 31 de dezembro de 2014), composto por debêntures a pagar, conforme mencionado na nota explicativa $\mathrm{n}^{\circ} 14$. A Companhia negociou financiamento de longo prazo para liquidar o empréstimo ponte e financiar a fase final de obras.

Este balanço patrimonial é explícito no que tange à demonstração e confirmação do comportamento das empresas que compõem a concessão do VLT na OUCRPRJ. Isto quer dizer que este balanço e, mais especificamente, o trecho acima corrobora a ideia de que as empresas responsáveis pelas obras de infraestrutura urbana investem no mercado financeiro, movimentando capital oriundo da venda de $\mathrm{CEPACS}^{8}$, portanto imobiliário, para a esfera financeira (momento do passivo circulante) e, posteriormente, resgatando esta aplicação com juros e lucros adicionais (momento do ativo circulante). Dessa maneira, o balanço patrimonial da concessionária revela que R 544 milhões e 895 mil estão aplicados em debêntures que foram pagos em janeiro de 2016. Além do investimento em debêntures, observa-se que foram aplicados no setor financeiro R $\$ 10$ milhões e 206 mil do total da composição do ativo não circulante e R\$ 1 milhão e 293 mil do passivo não circulante foi investido em operações de derivativos. No que se refere ao passivo circulante, investiu-se $\mathrm{R} \$ 7$ milhões e 336 mil em derivativos. Deve-se perceber que os passivos referentes a transações no mercado financeiro se tornarão ativos quando puderem ser realizados enquanto forma-dinheiro pelo fato de que as transações financeiras geram lucros futuros e por isso são, por essência, especulativas.

A extrema flexibilidade na movimentação de capital na contemporaneidade é, justamente, um dos condicionantes da passagem facilitada e lucrativa de capital de um setor da economia para outro. A integração entre a esfera financeira e o setor imobiliário é apontada por Danilo Volochko (2015, p.102):

Em meados da década de 1990 e dez anos depois, em meados dos anos 2000, ocorrem importantes aproximações entre o setor imobiliário e o capital financeiro, que caminham no sentido de incluir cada vez mais os negócios imobiliários no âmbito dos negócios financeiros, como o surgimento, de acordo com Botelho, de novos instrumentos financeiros que permitiram a transformação de bens imóveis em títulos mobiliários: os Fundos de Investimento Imobiliário (FII) e os Certificados de Recebíveis Imobiliários (CRI).

Os dados apresentados no balanço patrimonial do VLT revelam a articulação entre capital financeiro, imobiliário e o Estado, e, neste sentido, pode-se observar que esta PPP não é panaceia para os problemas fiscais da cidade nem tampouco para as lacunas na infraestrutura urbana. A infraestrutura urbana que está sendo criada (re-criada) na região portuária serve como base de atração para investimentos privados numa condição em que esta própria infraestrutura é fruto da reprodução do capital oriundo de agentes econômicos e do Estado. Assume-se neste artigo, portanto, que a produção do espaço urbano se tornou fundamental para a reprodução do capital em um momento histórico onde há, por muitas vezes, excedente de capital, o qual é convertido no espaço por meio de sua produção. 


\section{METODOLOGIA}

A análise realizada neste artigo parte da noção de totalidade social, por meio da qual faz-se essencial considerar todos os processos que se relacionam a determinado fenômeno com o objetivo de se pretender a uma análise dialética e aberta da realidade. Além disto, analisa-se a produção do espaço da OUCRPRJ de forma multiescalar, pois os agentes sociais responsáveis pela produção deste espaço se encontram em condições e escalas sociais desiguais, refletidas na posição de dominação exercida pelo BIRD / Banco Mundial e pelo poder público municipal em relação aos moradores do espaço onde se concretiza a OUCRPRJ, por exemplo.

À noção de totalidade, associa-se uma tentativa de análise da realidade a partir do método materialista histórico e dialético, cujo mote essencial é analisar os processos históricos a partir de sua materialidade, isto é, por meio da compreensão analítica dos processos e relações sociais que engendram determinados fenômenos em dado momento histórico.

\section{CONSIDERAÇÕES FINAIS}

A articulação entre capital financeiro e imobiliário é uma realidade na produção do espaço urbano contemporâneo e, portanto, deve ser investigada pois transforma o espaço tanto em sua forma como em seu conteúdo social. A materialização da Operação Urbana Consorciada da Região do Porto do Rio de Janeiro expressa espacialmente este processo, o qual é orientado por práticas neoliberais. Este processo de articulação gerou o movimento de capital oriundo da esfera financeira (momento da atuação especulativa dos FIIs) em direção ao setor imobiliário (momento da construção de empreendimentos por meio da aquisição de CEPACS e da realização das obras de infraestruturas) e, finalmente, seu retorno ao setor financeiro (momento da realização de investimentos financeiros através, majoritariamente, da aquisição de debêntures e derivativos, como foi comprovado através da análise do balanço patrimonial da Concessionária do VLT Carioca S.A). Estabelece-se, desta forma, o seguinte movimento de passagem do capital: setor financeiro - setor imobiliário - setor financeiro.

Sendo assim, em última análise, este é o movimento do capital dentro do perímetro da OUCRPRJ no que tange ao pagamento pela aquisição de CEPACS e ao seu retorno às empresas do setor imobiliário envolvidas na realização das obras de infraestruturas do perímetro. Pontua-se que as ações que promovem a reestruturação urbana da região portuária da cidade do Rio de Janeiro não advêm das relações entre coisas, mas sim de sujeitos sociais em relação ${ }^{9}$ (MARX, 2013) os quais disponibilizam seu capital com um fim específico: sua reprodução. A consolidação do sistema de crédito ainda no século XIX, seu aperfeiçoamento ao longo do século XX associado às práticas neoliberais imprimem uma dinâmica específica à produção espacial contemporânea, a qual não está mais direta e exclusivamente ligada ao movimento do capital imobiliário (produtivo), mas move-se por meio da lógica financeira.

Diante disso, pode-se observar que a produção do espaço que compõe a OUCRPRJ se enquadra no processo contemporâneo de financeirização da economia e das práxis fetichizada (KOSIK, 1969) em geral, no qual o objetivo essencial é a reprodução continuada de capital e não a produção de espaços que sejam compartilhados por todos enquanto valores de uso que promovem a reprodução da vida. Nestas circunstâncias, esta reprodução (de capital) é garantida em sua plenitude por meio da esfera financeira em aliança com o Estado neoliberal. 
Nesta perspectiva, conclui-se esta análise focada na produção do espaço da OUCRPRJ sob a égide do neoliberalismo financeirizado, com uma proposta de reflexão sobre este momento específico da produção espacial. Sendo assim, acerca da relação direta entre neoliberalismo e o processo de financeirização, Gérard Duménil e Dominique Lévy (2005, pp.86-87) apontam que:

O termo neoliberalismo é, em parte, adequado e inadequado, ou seja, enganador. Ele remete à liberdade dos mercados, a qual deve ser entendida como a liberdade do capital. Não se pode deduzir que o Estado tenha perdido toda função. O neoliberalismo se impôs sob a proteção do Estado. É preciso, igualmente, estender esta análise para o plano internacional e ter presente o papel paraestatal que as instituições financeiras internacionais, o FMI em primeiro lugar, desempenham na extensão da ordem neoliberal. Para definir o neoliberalismo, é necessário recorrer a uma teoria da sociedade, quer dizer, das classes e do Estado, de inspiração marxista. Fundamentalmente, o neoliberalismo corresponde à reafirmação do poder da finança depois de um período de perda de hegemonia; trata-se, assim, do segundo período de hegemonia da finança. No capitalismo, a propriedade dos meios de produção define de maneira inequívoca a classe dominante, mas essa propriedade se manifesta sob diferentes formas institucionais, que se modificam ao longo do tempo. Originalmente, referia-se à propriedade individual e familiar das empresas, cuja gestão estava sob controle direto dos proprietários. Essa relação de propriedade evoluiu até a propriedade financeira das sociedades (quer dizer, exercida por intermédio da posse de títulos), em que o poder dos proprietários se concentra nas instituições financeiras. Essas instituições cristalizam os interesses de grupos mais ou menos amplos (como faz uma holding financeira) ou coletivos (como um banco central). Denominamos finança a fração superior das classes capitalistas e as instituições onde se concentra sua capacidade de ação. Note-se que, nessa definição, é preciso distinguir finança do setor financeiro. Por um lado, a finança reúne uma fração de classe e instituições financeiras. Por outro, essas instituições financeiras constituem um conjunto mais vasto do que o que se pode agrupar em uma "indústria financeira"; compreendem igualmente instituições como os fundos de pensão e o banco central, que têm funções e modos de funcionamento diferentes, por exemplo, dos de outros bancos.

\section{NOTAS}

1 - Apesar da circulação de capital e mercadorias enfrentar barreiras cambiais, estas são facilmente transponíveis através de acordos e isenções de taxações. Portanto, as barreiras cambiais não se configuram, necessariamente, como obstáculos à circulação livre de capital e mercadorias no mundo atual.

2 - BANCO INTERNACIONAL PARA RECONSTRUÇÃO E DESENVOLVIMENTO/BANCO MUNDIAL, Cities in transition: World Bank Urban and Local Government Strategy, Washington, 2000.

3 - Para maior aprofundamento acerca da CFI, buscar em: $<$ http://www.ifc.org/wps/wcm/connect/Multilingual_Ext_Content/IFC_External_Corpor ate_Site/Home_PT>.

4 - Pode-se inferir do contexto que se referem a desastres naturais.

5 - Retirado de: The World Bank. Implementation, completion and results report (IBRD -8010). Report $N^{\text {o: }}$ ICR2522, 2013, p.4. Para aprofundamento deste tema, consultar: The 
World Bank. Implementation, completion and results report (IBRD -8010). Report $\mathrm{N}^{\mathrm{o}}$ : ICR2522, 2013, pp.13-14.

6 - BIRD/BANCO MUNDIAL, Cidades em movimento: estratégia de transporte urbano do Banco Mundial. São Paulo: Sumatra Editorial, 2003. Disponível em: <http://siteresources.worldbank.org/INTURBANTRANSPORT/Resources/portuguese cities_on the move.pdf $>$.

7 - Para aprofundamento do tema buscar informações no seguinte sítio eletrônico: <http://www.portonovosa.com/pt-br/sobre-a-concessionaria $>$.

8 - O capital que entra no caixa da concessionária através de aportes públicos e de contraprestação pecuniária advém do FIIVLT e da Prefeitura da Cidade. Deve-se ter em mente que o capital adquirido pelo poder público com a venda dos CEPACS fica retido em fundos de investimento com o intuito de ser utilizado como pagamento das obras infraestruturais. Apesar da Prefeitura afirmar que este capital fica apenas retido no FIIPM, pode-se deduzir que ele é também direcionado ao FIIVLT para cobrir os gastos com a implantação do VLT porque não existe comercialização de CEPACS ligada à construção do VLT. Portanto, infere-se que existe o redirecionamento dos recursos retidos no FIIPM em direção ao FIIVLT para concretizar sua implementação.

9 - A respeito da crítica marxiana relativa à ideia de "relação entre coisas" quando na realidade se tem "relação entre sujeitos sociais", buscar aprofundamento do tema em: Marx, Karl. O capital: crítica da economia política: Livro I: o processo de produção do capital. São Paulo: Boitempo, 201, p.148).

\section{REFERÊNCIAS BIBLIOGRÁFICAS}

BANCO INTERNACIONAL PARA RECONSTRUÇÃO E DESENVOLVIMENTO/BANCO MUNDIAL, Cidades em movimento: estratégia de transporte urbano do Banco Mundial. São Paulo: Sumatra Editorial, 2003.

BANCO INTERNACIONAL PARA RECONSTRUÇÃO E DESENVOLVIMENTO/BANCO MUNDIAL, Cities in transition: World Bank Urban and Local Government Strategy, Washington, 2000.

CARLOS, Ana Fani Alessandri (org.). Crise urbana. São Paulo: Contexto, 2015.

CHESNAIS, François. A mundialização do capital. São Paulo: Xamã, 1996.

DELLOITE TOUCHE TOHMATSU AUDITORES INDEPENDENTES. Concessionária do VLT Carioca S.A: Informações financeiras intermediárias referentes ao trimestre e semestre findos em 30 de junho de 2015 e Relatório de revisão dos auditores independentes sobre as informações financeiras intermediárias. São Paulo, 2015.

DUMÉNIL, Gérard; LÉVY, Dominique. O neoliberalismo sob a hegemonia norteamericana. In: CHESNAIS, François (org.). A finança mundializada: raízes sociais $e$ políticas, configuração, consequências. São Paulo: Boitempo, 2005. P. 85-108. 
HARVEY, David. O neoliberalismo: História e implicações. São Paulo: Loyola, 2008

KOSIK, Karel. Dialética do concreto. Rio de Janeiro: Editora paz e Terra, 1969.

LEFEBVRE, Henri. A produção do espaço. Trad. Grupo "As (Im)possibilidades do urbano na metrópole contemporânea do Núcleo de Geografia Urbana da UFMG. (do original: La production de l'espace. $4^{\mathrm{a}}$ éd. Paris: Éditions Anthropos, 2000).

MARX, Karl. O capital: crítica da economia política: Livro I: o processo de produção do capital. São Paulo: Boitempo, 2013.

VOLOCHKO, Danilo. A moradia como negócio e a valorização do espaço urbano metropolitano. In: CARLOS, Ana Fani Alessandri; Volochko, Danilo; Alvarez, Isabel Pinto (Org.). A cidade como negócio. São Paulo: Contexto, 2015. P.97-120. 